\title{
CALCULATION OF THE THERMAL STATE OF THE GRAPHITE MODERATOR OF THE RBMK REACTOR
}

\author{
Alexander V. Vorobiev ${ }^{1, *}$, Vitaly O. Dmitriev ${ }^{1}$, Ivan G. Tkachenko ${ }^{1}$, and Alexander S. \\ Matveev $^{1}$ \\ ${ }^{1}$ Tomsk Polytechnic University, 634050, Tomsk, Russia
}

\begin{abstract}
This work is devoted to study the temperature field of the graphite stack of the RBMK reactor. In work was analyzed the influence of contact pressure between the components of the masonry on the temperature of the graphite moderator.
\end{abstract}

\section{Introduction}

One of the factors that determine the reliability and safety of NPP with reactors watergraphite reactor is the reliability of graphite moderator (masonry), calculated for the whole lifetime of the reactor.

The graphite walls of the reactor RBMK-1000 has a cylindrical shape with a diameter of $11.8 \mathrm{~m}$ and height $7 \mathrm{~m}$, made up of 2488 columns. In the holes of the columns there are pipes of the technological channels (TC) and CPS channels. Fuel assemblies are located inside the channels are cooled by water with a temperature of $250-280^{\circ} \mathrm{C}$.

During the reactor operation part (5-6\%) of the full thermal power of the reactor is highlighted in graphite masonry. This heat is removed to the pipes TC. To ensure thermal contact with the blocks on the pipe channels wearing split graphite rings (Fig. 1), and in the gaps between the pipes and blocks the purge gas is supplied (a standard composition of 10 $\%$ nitrogen and $90 \%$ helium by volume).

The design and schematic solutions of reactor facilities RBMK allow for changes in the composition of the purge gas [1].

Temperature field in the graphite walls is determined primarily by the capacity of the reactor. The content of nitrogen $X_{N}$ in the nitrogen-helium mixture (the composition of the purge gas) effects on the temperature of graphite.

The temperature of the graphite masonry is one of the main parameters limiting the operation of RBMK reactor. In practice, it is assumed that all modes of reactor operation the maximum temperature of the graphite should not exceed the values of threshold temperature $750-800{ }^{\circ} \mathrm{C}$ [1-3]. In addition, fluctuations in the average temperature of the graphite masonry (moderator) lead to corresponding changes in the reactivity of the reactor,

*Corresponding author: worob@tpu.ru 
as these units are RBMK reactors offer a significant magnitude positive effect of reactivity on the temperature of the moderator [1].

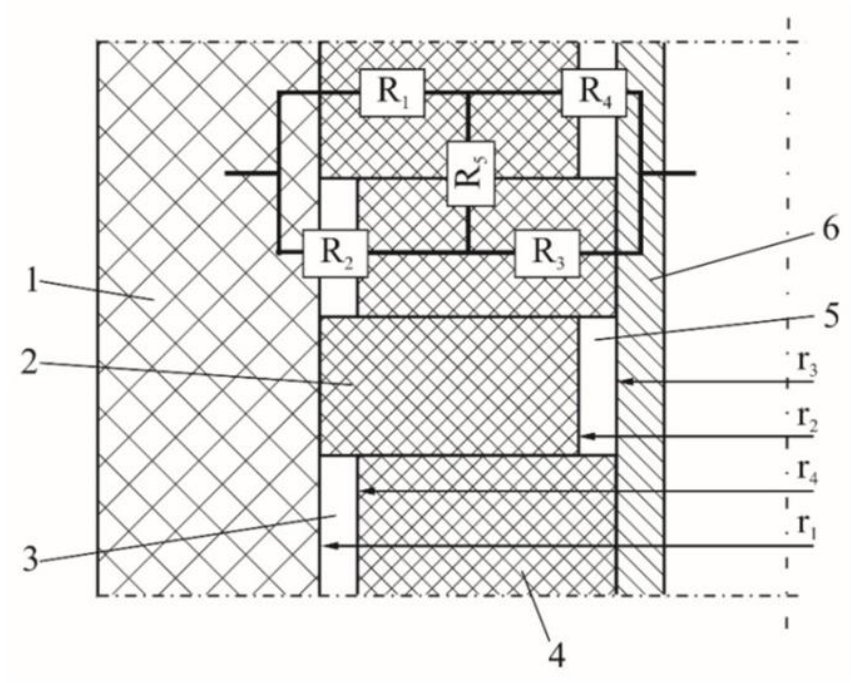

Fig. 1. The scheme of installation of the pipe TC in graphite masonry: 1 - graphite block; 2 - outer graphite ring (sleeve); 3, 5 - gas gaps; 4 - inner graphite ring (bushing); $R_{i}$ - thermal resistance; $r_{i-}$ is the radius.

Consequently, the definition of the thermal state of the graphite stack of the RBMK reactor is an urgent task.

Temperature field of masonry water-graphite reactor is three-dimensional. Program of numerical calculations of two-dimensional and three-dimensional temperature fields very difficult $[4,5]$. Therefore, for an approximate estimation of the maximum temperature of the graphite is necessary to resort to various simplifications and assumptions.

\section{The calculations and methodology of the study}

In the method (3) thermal resistance of the bushings and the gas gaps can be likened to the electrical resistance. Making and simplifying the circuit of these resistances, it is possible to determine the value of the equivalent circuit, and hence the thermal resistance of the gap of the graphite block - pipe and technological channel (Fig. 1).

The reasons for this discrepancy may be unaccounted thermal resistance at the contact graphite block outer ring, outer ring and inner ring, the inner ring pipe of the TC (Fig. 1).

To clarify the source of differences between calculated and experimental data on the temperature of the graphite technique was refined by incorporating additional thermal contact resistances. To calculate the last used criteria equation from [6].

$$
\alpha_{k}=\frac{\lambda_{m x} \cdot Y}{h_{0}}+8 \cdot 10^{3} \cdot \lambda_{a v} \cdot\left(\frac{P_{k}}{3 \cdot \sigma_{s t r}} \cdot K\right)^{0,86} .
$$

Where $\lambda_{m x}$ - thermal conductivity of gas mixture; $Y=3.33$ - the relative values of the gap; $h_{0}$ - the total roughness of the contacting surfaces; $K$ - is the coefficient depending on $h_{0} ; P_{k}$ - contact pressure ; $\sigma_{s t r}$ - the tensile strength of more plastic of the contacting materials. 
By using this method were calculated the temperature of individual graphite block with variation of the composition of the purge mixture and the amount of contact pressure. The calculation results are presented in Fig. 3.

\section{Experimental results}

The results of the variant calculations of temperature separate the graphite block is considered the technique shown in Fig. 2.

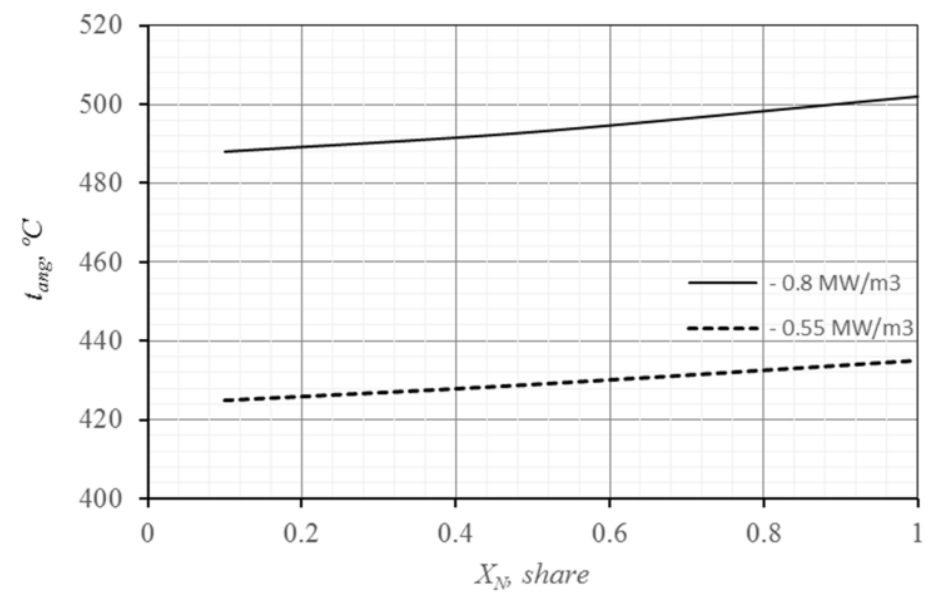

Fig. 2. The dependence of the maximum temperature of the graphite block (in the corner of graphite block) from the composition of the purge mixture excluding thermal contact resistance.

Content analysis Fig. 2 shows that the maximum (angular) temperature of the graphite block $t_{\text {ang }}$ with increasing content of nitrogen in the purge mixture from 10 to $100 \%$ increase by $10-15^{\circ} \mathrm{C}$. These figures differ significantly from the experimental data given in [2], where the mean value of the coefficient of the effect of mixture composition on the temperature of the graphite is estimated in the range of $0.9-1.2{ }^{\circ} \mathrm{C} / \%$.

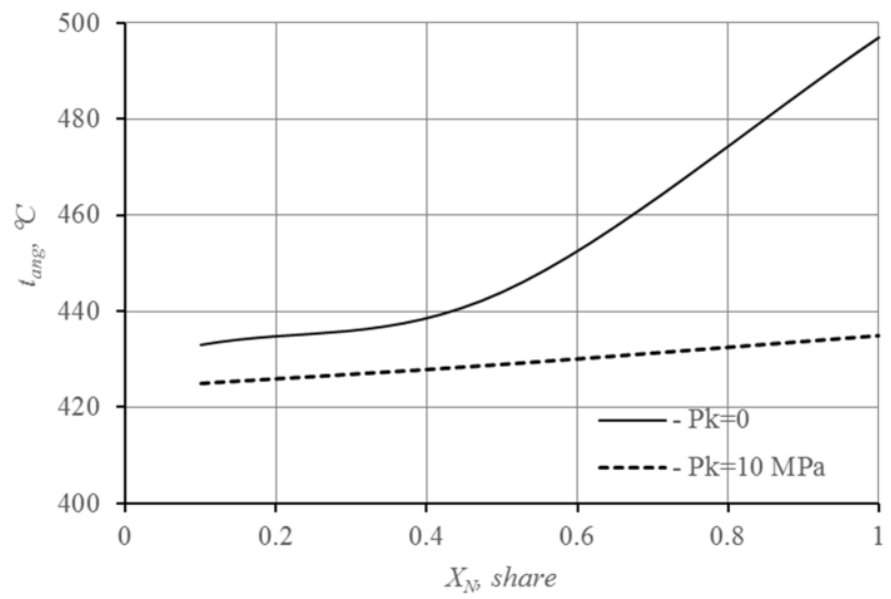

Fig. 3. The dependence of the maximum temperature of the graphite block (in the corner of graphite block) from the composition of the purge mixture at different values of contact pressure. 
The analysis of graphs in Fig. 3 shows that the thermal contact resistance is estimated significantly (1.05-1.2 times) increase the temperature of the graphite moderator. It also increases significantly the degree of influence of nitrogen content in the mixture to the temperature level of the unit.

\section{Conclusion}

As a result of work were revised algorithm and program of calculation of the thermal state of the graphite moderator of the RBMK reactor, taking into account thermal resistance at the contact elements of the graphite stack and TC.

The use of this program allows to significantly improve the accuracy of engineering methods of calculation of the temperature of the graphite moderator of the RBMK reactor.

\section{References}

1. N. A. Dollezhal, Channel nuclear power reactor (Atomizdat, Moskow, 1980) [in Russia]

2. A. V. Vorob'ev, A. M. Antonova, Bulletin of the Tomsk Polytechnic University 322, 182 (2013)

3. A.V. Vorobiev, A.M. Antonova, M.P. Vinogradov, EPJ Web of Conf. 110, 01053 (2016)

4. A.M. Race, Thermal-hydraulic calculation of the reactor RBMK-1000 reactors: textbook (MEI, Moscow, 1982) [in Russia]

5. D.V. Gvozdyakov, A.O. Tanishev, S.A. Shvab, V.N. Martyshev, A.V. Kuzmin, MATEC Web of Conf., 37, 01024 (2015)

6. Y. P. Shlykov, E. A. Ganin, S.N. Tsarevsky, The thermal contact resistance (Energy, Moscow, 1977) [in Russia] 